\title{
A Survey of Primary Care Offices: Triage of Poisoning Calls without a Poison Control Center
}

\author{
Travis Austin, ${ }^{1}$ Daniel E. Brooks, ${ }^{2,3}$ Sharyn Welch, ${ }^{3}$ and Frank LoVecchio ${ }^{2,3}$ \\ ${ }^{1}$ University of Arizona College of Medicine, Phoenix, AZ 85004, USA \\ ${ }^{2}$ Department of Medical Toxicology, Banner Good Samaritan Medical Center, 925 East McDowell Road, 2nd Floor, Phoenix, \\ AZ 85006, USA \\ ${ }^{3}$ Banner Good Samaritan Poison and Drug Information Center, Phoenix, AZ 85006, USA
}

Correspondence should be addressed to Daniel E. Brooks, daniel.brooks@bannerhealth.com

Received 22 March 2012; Revised 18 April 2012; Accepted 22 April 2012

Academic Editor: Jens Sondergaard

Copyright (c) 2012 Travis Austin et al. This is an open access article distributed under the Creative Commons Attribution License, which permits unrestricted use, distribution, and reproduction in any medium, provided the original work is properly cited.

Poison control centers hold great potential for saving health care resources particularly by preventing unnecessary medical utilization. We developed a four-question survey with three poisoning-related scenarios, based on common calls to our poison center, and one question regarding after-hours calls. We identified primary care provider offices in our poison center's region from an internet search. We contacted these offices via telephone and asked to speak to an office manager or someone responsible for triaging patient phone queries. Using a scripted form, trained investigators questioned 100 consecutive primary care provider offices on how they would handle these poisoning-related calls if there was no poison center to refer their patients to. Results of our survey suggest that $82.5 \%$ of poisoning-related calls to primary care offices would be referred to 911 or an emergency department if there was no poison center. These results further support the role that poison centers play in patient care and health care utilization.

\section{Background}

In 2009 US poison control centers (PCCs) handled over 4.2 million calls related to poisonings, drug information, and environmental exposures (e.g., envenomations), including almost 2.5 million human exposures [1]. Over $90 \%$ of these exposures occurred at the caller's residence and $72.5 \%$ were managed on site, thereby not requiring an evaluation at a health care facility. These numbers of calls and percentage of on-site management have been consistent for several years [2].

Past work has shown that PCCs can save health care resources [3-11] including the prevention of unnecessary emergency department (ED) visits, and decrease lengths of stay for poisoned patients [4, 12-14]. One study, involving 2007 data from our single PCC, showed a median savings of $\$ 33$ million in unnecessary health care charges by managing patients at home [11]. A report from the United States Institute of Medicine estimates that the combined activities of all US PCCs save more than $\$ 900$ million annually [15, 16]. Other reviews have identified the importance of maintaining government's financial support of PCCs, $[15,17]$ including one cost analysis that offered an appropriate summary by concluding that "poison control centers offer a large return on investment" [18]. Despite these data PCCs continue to be challenged with budget cuts $[17,19,20]$.

Our PCC routinely conducts quality assurance surveys to identify our need and role within our community. We interview callers and health care providers on several issues including their satisfaction with our services, evolving needs, and alternative plans if our center were to close. We hypothesized that primary care providers (PCPs) would refer most poisoning-related calls to Emergency Medical Services (EMS), which we defined as 911 services or an ED, if our PCC were to close.

\section{Method}

We conducted a cross-sectional telephone survey of PCP offices in our PCC's service region. Adult, family practice, and pediatric PCP offices were identified via an internet search, and phone numbers were recorded. We developed a scripted survey (see Appendix) that included an introductory statement (that identified the caller and the purpose of 
the call), three poisoning-related scenarios based on common calls to our PCC, and a fourth question related to afterhours calls. Trained investigators contacted PCP offices via telephone and asked to speak with an office manager or triage personnel who would handle a call from a patient or a patient's caregiver. After identifying an appropriate staff member, a structured phone interview was conducted. Each question was asked along with the four offered responses. All answers were recorded on a data abstraction sheet. All responses that did not fit into a predetermined answer were recorded under the category "other."

If the interview was not conducted on the first call, we left a message with a call back number. All offices not returning our message were called a second time. If there was no response after two calls or messages, the office was listed as a refusal to participate. The first 100 consecutively completed surveys were recorded and analyzed. Responses for discrete variables were totaled and reported as percentages. This was a quality assurance project that was exempt from IRB approval.

\section{Results}

A total of 206 PCP offices were initially identified; 133 $(64.5 \%)$ were contacted before 100 completed surveys were recorded. (Figure 1) Of the 33 offices not included, 20 (61\%) refused participation and $13(397 \%)$ were identified as nonPCP practices or had a nonworking telephone number. The survey results are represented in Tables 1 and 2. Overall, $82.5 \%$ of responses resulted in a patient referral to EMS (i.e., an ED or 911).

For the first question, "The patient (child) had an accidental ingestion of an unknown pill," 92 subjects (92\%) would refer the patient to an $\operatorname{ED}(n=59)$ or $911(n=$ 33). For the second question, "The patient (child) had an accidental exposure to fumes from an oven cleaner and was coughing with eye and throat irritation," 90 subjects (90\%) would refer the patient to an $\operatorname{ED}(n=45)$ or $911(n=45)$. For the third question, "The patient (child) was stung on the foot by a scorpion and was crying with localized pain and paresthesias," 70 subjects $(70 \%)$ would refer the patient to an $\operatorname{ED}(n=52)$ or $911(n=18)$.

Responses to the first three questions that were recorded in the "Other" category included "referral to an urgent care or pharmacy" ( $n=3)$, "referral to urgent care" $(n=2)$, and "talk to the provider about advice" $(n=3)$.

For the fourth question, "Would there be a difference in handling these scenarios for after-hour calls," 25 subjects (25\%) said "no." The 75 "yes" responses included "send to the $\operatorname{ED}^{\prime}(n=46)$, "page the oncall MD" $(n=17)$, "call 911" $(n=11)$, and "refer to a nurse line" $(n=1)$.

After combining the results for all questions, the overall rate of PCP referral of poisoning-related calls to EMS was $82.5 \%$. This was determined by averaging the results of questions one through three ( $92 \%, 90 \%$, and $70 \%$, respectively), with the total EMS referrals for question four (84\%). The total EMS referrals for question four was determined by adding the number of "yes" responses (that included refer to EMS; $n=57$ ) with the number of "no" responses ("no" there

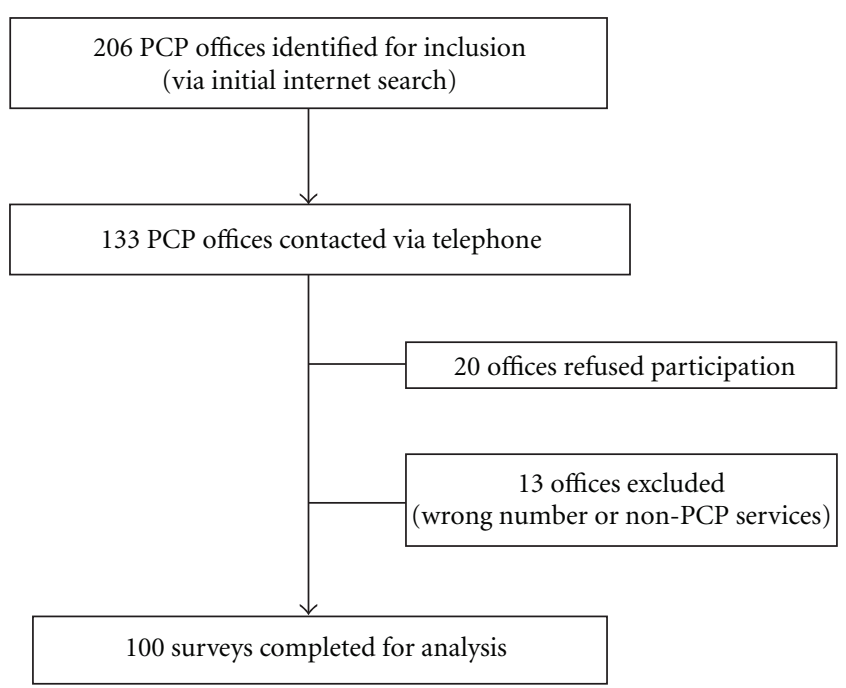

FIGURE 1: Survey data: selection and exclusion of PCP offices.

would be no difference for after-hours calls) that represented a referral to EMS. To determine this number, we multiplied the "no" response $(n=25)$ by the average percentage of EMS referrals for questions one through three (84\%), resulting in an additional 21 referrals. We then added this number of "no" responses $(n=21)$ to the number of "yes" responses $(n=57)$ and determined the final number of $78(78 \%)$ for question four. Combining the percentages of EMS referrals for all four questions (no. $1=92 \%$, no. $2=90 \%$. no. $3=70 \%$ and no. $4=78 \%$ ) resulted in an overall average of $82.5 \%$.

\section{Discussion}

Previous work has tried to identify factors associated with healthcare utilization following poisoning-related illness, including patient or care-giver decisions and awareness of PCCs as a resource $[3,10]$. Kearney et al. determined that $100 \%$ of surveyed EDs $(n=38)$ but only $82 \%$ of private physician offices $(n=114)$ would contact a PCC when dealing with a call from the public concerning a poisoning [3]. Of interest only $64 \%$ of the surveyed PCP offices in that study would refer a potentially poisoned patient to an ED, 911, or a physician office. It is unknown what percentage of these patients would ultimately be referred into the caller's PCP office instead of utilizing EMS? Factors associated with our increased rate of EMS referral $(82.5 \%$ compared to, at most, 64\%) are unknown, but may include increased private physicians' workload, increased fear of adverse patient outcome without immediate medical attention, or increased awareness of PCCs.

There are limited data concerning the involvement of PCCs for the care of patients admitted for poisoningrelated illnesses. One study found that, overall, a regional PCC was consulted for only $18.1 \%$ of patients discharged after hospitalization for an accidental poisoning [4]. These authors found a higher PCC consultation rate for younger patients: $41.9 \%$ consultation rate for patients under six years of age compared to $6.7 \%$ for patients greater than 55 years of age. Using the National Electronic Injury Surveillance 
TABLE 1: PCP survey results; questions no. 1-3 (poisoning-related scenarios).

\begin{tabular}{|c|c|c|c|c|c|}
\hline \multirow{2}{*}{$\begin{array}{l}\text { Survey questions } 1-3 \\
\text { "Assuming there were no regional poison control centers" }\end{array}$} & \multicolumn{5}{|c|}{ Responses to questions $(n=100)$} \\
\hline & Come to the office & Call 911 & Go to the ED & Other & 911 or $\mathrm{ED}$ \\
\hline (1) The patient had an accidental ingestion of an unknown pill? & 5 & 33 & 59 & 3 & 92 \\
\hline $\begin{array}{l}\text { (2) The patient had an accidental exposure to fumes from an oven } \\
\text { cleaner and has eye and throat irritation? }\end{array}$ & 7 & 45 & 45 & 3 & 90 \\
\hline $\begin{array}{l}\text { (3) The patient was stung on the foot by a scorpion and is having } \\
\text { localized pain and paresthesias? }\end{array}$ & 28 & 18 & 52 & 2 & 70 \\
\hline
\end{tabular}

TABLE 2: PCP survey results; question no. 4 (after-hours calls).

\begin{tabular}{|c|c|c|}
\hline Survey question 4 & No & Yes \\
\hline $\begin{array}{l}\text { (4) Would there be a difference } \\
\text { in handling these scenarios } \\
\text { for after-hours calls? }\end{array}$ & 25 & $\begin{array}{l}75 \text { (Send to the } E D=46 ; \\
\text { page oncall MD-17; call 911- } \\
11 \text {; refer to nurse line- } 1 \text { ) }\end{array}$ \\
\hline
\end{tabular}

System, another study determined that a PCC was only contacted in about $19 \%$ of poisoning exposures, in patients under six years old, which resulted in an evaluation at a healthcare site [10].

Burkhart et al. evaluated the utilization of their regional PCC by ED and PCP physicians by using a 23-question survey [21]. With a response rate of nearly $40 \%(n=715)$, these authors found that overall, $67 \%$ of the responding physicians had used PCC services within the past year. However, there was a much higher rate of PCC utilization among ED physicians (98.7\%) compared to PCP physicians (65.3\%). The reasons that these physicians called the PCC included assistance with poisoned patients (95\%), poison education information (70\%), identification of adverse drug reactions $(46 \%)$, and drug identification $(41 \%)$. Interestingly, despite overwhelming use of PCC services, responding ED physicians failed to report "approximately 50\%" of their total poisoning cases.

Our data provide additional support of the role that poison centers play in saving health care resources. Through our role as a resource for PCP offices we help triage, and care for, patients with poisoning-related medical issues.

There are several limitations of this study, including the potential for selection bias and limited external validity. We included three poisoning-related scenarios based on our local experiences. These calls do not represent typical calls to PCCs, or PCP offices, in other areas of our country. Also, using a scripted survey, respondents were only offered a limited amount of patient information. It is possible that other decisions would have been made (e.g. home observation) if additional questions could have been asked and answered. In terms of selection bias, an office staff more supportive of the PCC may have been more likely to participate in the study. Offices with triage protocols or on-going staff education may feel more comfortable with handling poisoning-related issues and therefore may not have agreed to participate in the survey. Although we did not encounter any respondents that suggested this to be true, potential bias exists. Lastly, it is unknown how many of these fictitious patients, if referred to our PCC, would ultimately have been referred to EMS despite our involvement? However, during the study period our center managed $74 \%$ of human exposures onsite (e.g., at home) without referral to a health care facility.

\section{Conclusions}

Based on our survey, $82.5 \%$ of poisoning-related calls to primary care offices in our region would be referred to 911 or an ED if our poison center closed. These results support the role of poison control centers as a community asset by assisting with patient care and saving health care resources.

\section{Appendix}

\section{Survey of PCP Offices regarding Poisoning-Related Issues}

"Hello, my name is behalf of the Banner Good Samaritan Poison and Drug Information Center. I was hoping to speak with the office manager or any staff member who would triage a phone call from a patient. We have four short questions regarding poison center support and patient care that I would like to ask you. Assuming that the regional poison center was closed; if a patient or parent called in to your office with one of the following questions, what would you advise?"

(1) The patient (child) had an accidental ingestion of an unknown pill?
Ask patient to come into the office
Instruct the patient to call 911
Instruct the patient to go to the $\mathrm{ED}$
Other:

(2) The patient (child) had an accidental exposure to fumes from an oven cleaner and was coughing with eye and throat irritation?
Ask patient to come into the office
Instruct the patient to call 911
Instruct the patient to go to the ED
Other:

(3) The patient (child) was stung on the foot by a scorpion and was crying with localized pain and paresthesias?

Ask patient to come into the office

Instruct the patient to call 911

Instruct the patient to go to the $\mathrm{ED}$

Other: 
(4) Would there be a difference in handling these scenarios for after-hours calls?

\section{No}

Yes (if so how):

\section{References}

[1] A. C. Bronstein, D. A. Spyker, L. R. Cantilena Jr., J. L. Green, B. H. Rumack, and S. L. Giffin, "2009 annual report of the American association of poison control centers' national poison data system (NPDS): 27th annual report," Clinical Toxicology, vol. 48, no. 10, pp. 979-1178, 2010.

[2] AAPCC website, 2011, http://www.aapcc.org/dnn/NPDSPoisonData/NPDSAnnualReports.aspx.

[3] T. E. Kearney, K. R. Olson, L. A. Bero, S. E. Heard, and P. D. Blanc, "Health care cost effects of public use of a regional poison control center," Western Journal of Medicine, vol. 162, no. 6, pp. 499-504, 1995.

[4] T. L. Bunn, S. Slavova, H. A. Spiller, J. Colvin, A. Bathke, and V. J. Nicholson, "The effect of poison control center consultation on accidental poisoning inpatient hospitalizations with preexisting medical conditions," Journal of Toxicology and Environmental Health, Part A, vol. 71, no. 4, pp. 283-288, 2008.

[5] C. Chafee Bahamon and F. H. Lovejoy Jr., "Effectiveness of a regional poison center in reducing excess emergency room visits for children's poisonings," Pediatrics, vol. 72, no. 2, pp. 164-169, 1983.

[6] D. L. Harrison, J. R. Draugalis, M. K. Slack, and P. C. Langley, "Cost-effectiveness of regional poison control centers," Archives of Internal Medicine, vol. 156, no. 22, pp. 2601-2608, 1996.

[7] N. R. Kelly, M. D. Ellis, R. T. Kirkland, S. E. Holmes, and C. A. Kozinetz, "Effectiveness of a poison center: Impact on medical facility visits," Veterinary and Human Toxicology, vol. 39, no. 1, pp. 44-48, 1997.

[8] W. D. King and P. A. Palmisano, "Poison control centers: can their value be measured?" Southern Medical Journal, vol. 84, no. 6, pp. 722-726, 1991.

[9] E. Zaloshnja, T. Miller, P. Jones et al., "The impact of poison control centers on poisoning-related visits to EDs-United States, 2003," American Journal of Emergency Medicine, vol. 26, no. 3, pp. 310-315, 2008.

[10] B. J. Polivka, M. Casavant, and S. D. Baker, "Factors associated with healthcare visits by young children for nontoxic poisoning exposures," Journal of Community Health, vol. 35, no. 6, pp. 572-578, 2010.

[11] F. LoVecchio, S. Curry, K. Waszolek, J. Klemens, K. Hovseth, and D. Glogan, "Poison control centers decrease emergency healthcare utilization costs," Journal of Medical Toxicology, vol. 4, no. 4, pp. 221-224, 2008.

[12] S. R. Offerman, "The clinical management of acetaminophen poisoning in a community hospital system: factors associated with hospital length of stay," Journal of Medical Toxicology, vol. 7, no. 1, pp. 4-11, 2011.

[13] Z. P. Vassilev and S. M. Marcus, "The impact of a poison control center on the length of hospital stay for patients with poisoning," Journal of Toxicology and Environmental Health, Part A, vol. 70, no. 2, pp. 107-110, 2007.

[14] V. Lee, J. F. Kerr, G. Braitberg et al., "Impact of a toxicology service on a metropolitan teaching hospital," Emergency Medicine, vol. 13, no. 1, pp. 37-42, 2001.
[15] H. A. Spiller and J. R. K. Griffith, "The value and evolving role of the U.S. Poison control center system," Public Health Reports, vol. 124, no. 3, pp. 359-363, 2009.

[16] Institute of Medicine Committee on Poison Prevention and Control and Board on Health Promotion and Disease Prevention, Forging a Poison Prevention and Control System, National Academies Press, Washington, DC, USA, 2004.

[17] T. Litovitz, T. E. Kearney, K. Holm, R. A. Soloway, R. Weisman, and G. Oderda, "Poison control centers: is there an antidote for budget cuts?" American Journal of Emergency Medicine, vol. 12, no. 5, pp. 585-599, 1994.

[18] T. R. Miller and D. C. Lestina, "Costs of poisoning in the United States and savings from poison control centers: a benefit-cost analysis," Annals of Emergency Medicine, vol. 29, no. 2, pp. 239-245, 1997.

[19] S. Giffin and S. E. Heard, "Budget cuts and U.S. poison centers-regional challenges create a nationwide problem," Clinical Toxicology, vol. 47, no. 8, pp. 790-791, 2009.

[20] B. Guyer, A. Mavor, J. Alexander et al., "Forging a poison prevention and control system: report of an institute of medicine committee," Ambulatory Pediatrics, vol. 5, no. 4, pp. 197-200, 2005.

[21] K. K. Burkhart, J. W. Donovan, and S. O’Donnell, “Utilization of a regional poison center by primary care and emergency physicians," American Journal of Emergency Medicine, vol. 13, no. 1, pp. 103-105, 1995. 


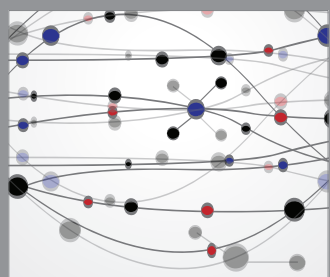

The Scientific World Journal
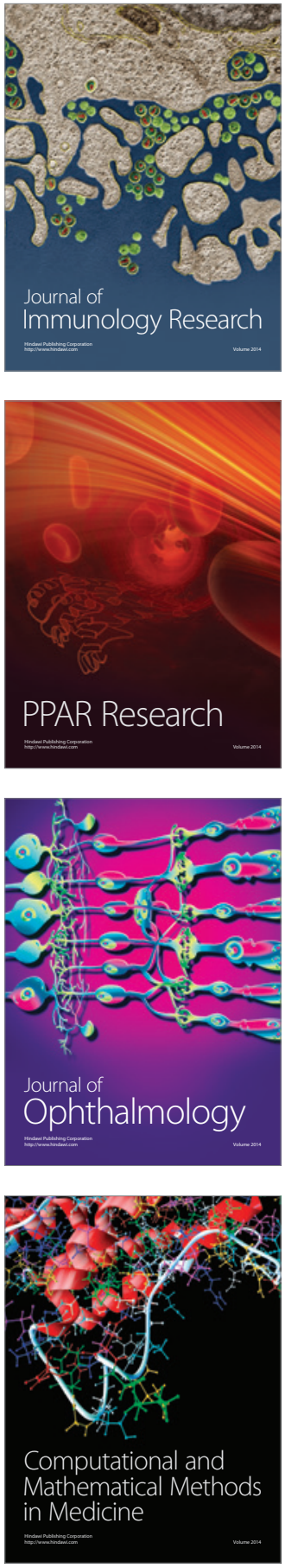

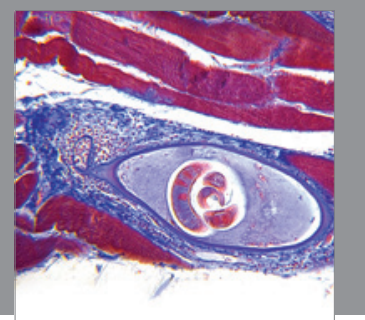

Gastroenterology

Research and Practice
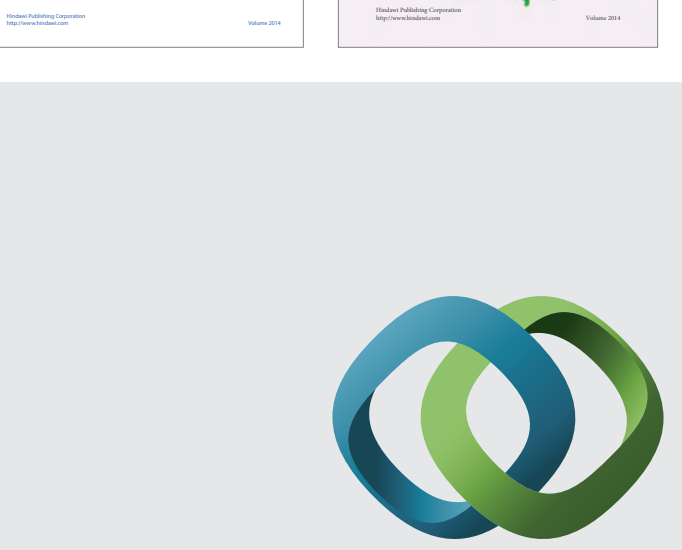

\section{Hindawi}

Submit your manuscripts at

http://www.hindawi.com
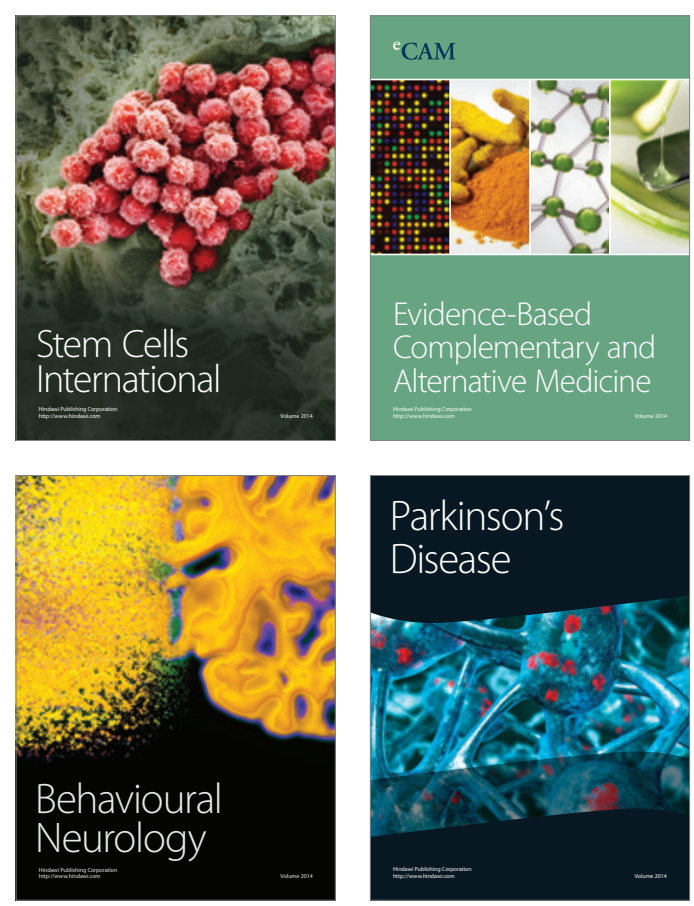

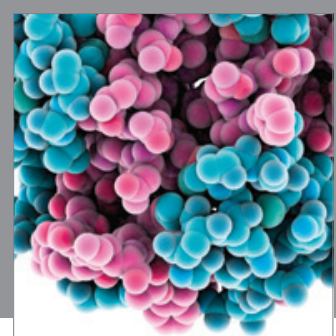

Journal of
Diabetes Research

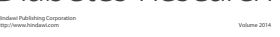

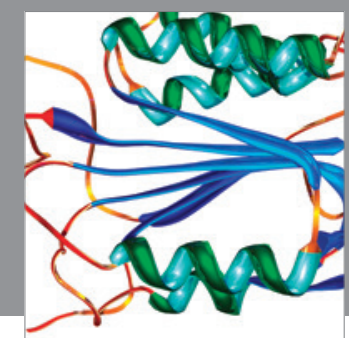

Disease Markers
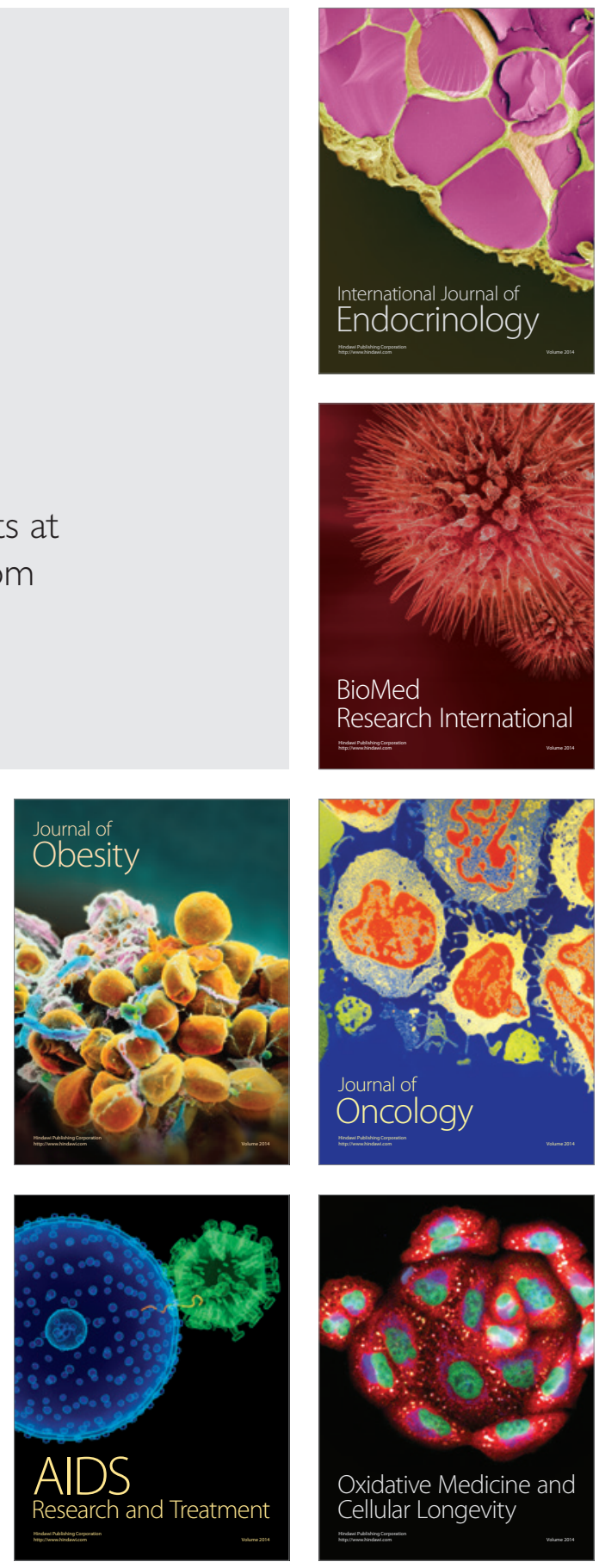